\title{
Solitary fibrous tumor of the lesser omentum mimicking stomach gastrointestinal stromal tumor
}

\author{
Seonghoon Kim', Jaehyuk Heo', Pyungsu Kim', Hyeseung Han², Hoyoon Bang' \\ Departments of ${ }^{1}$ Gastrointestinal Surgery and ${ }^{2}$ Pathology, Konkuk University Medical Center, Seoul, Korea
}

Solitary fibrous tumor (SFT) is a mesenchymal tumor that rarely occurs in the abdomen. We report a very rare case of an abdominal SFT in the lesser omentum. A 39-year-old Korean man was referred to our center for management of a $9 \mathrm{~cm}$ incidental mass in the abdominal space found on a chest computed tomography (CT) during a routine medical examination. He had no symptoms, and there were no specific findings on physical examination. A contrast enhancement CT was performed, and an extraluminal gastrointestinal stromal tumor in the stomach or a pancreatic origin mass was suspected. Surgery was performed and an enclosed mass in the lesser omentum was observed, which was resected completely. The postoperative course was uneventful. Based on microscopy, the omental tumor was diagnosed as SF.

Keywords: Solitary fibrous tumor, Abdominal cavity, Gastrointestinal stromal tumor

\section{INTRODUCTION}

Solitary fibrous tumor (SFT) is one of the tumors originating from mesenchymal cells. It was first found in the pleura in 1931 [1]. The true incidence is difficult to ascertain. However, a study done in a large referral center reported a prevalence of less than $2 \%$ [2]. SFT usually occurs in the pleural cavity, but it has been reported in various other parts such as the head, neck, abdomen, and pelvis [3-8]. Herein, we report a rare case of SFT in the lesser omentum. The study was exempted from approval by the Institutional Review Board of Konkuk University Medical Center (IRB exemption No. 2020-12-045) and the informed consent was waived.

Received: Jun 12, 2020 Revised: Nov 4, 2020 Accepted: Nov 30, 2020 Correspondence to: Hoyoon Bang Department of Gastrointestinal Surgery, Konkuk University Medical Center, 120-1 Neungdong-ro, Gwangjin-gu, Seoul 05030, Korea Tel: +82-2-2030-7598, Fax: +82-2-2030-7739

E-mail: hybang@kuh.ac.kr

ORCID: Seonghoon Kim (https://orcid.org/0000-0002-5804-4490), Jaehyuk Heo (https://orcid.org/0000-0001-6311-6674), Pyungsu Kim (https://orcid.org/00000002-1143-6278), Hyeseung Han (https://orcid.org/0000-0002-3591-9995), Hoyoon Bang (https://orcid.org/0000-0002-7164-3877)

Copyright (@) 2020 Korean Society of Surgical Oncology

This is an Open Access article distributed under the terms of the Creative Commons Attribution Non-Commercial License (http://creativecommons.org/licenses/by-nc/4.0) which permits unrestricted non-commercial use, distribution, and reproduction in any medium, provided the original work is properly cited.

\section{CASE REPORT}

A 39-year-old Korean man with no medical or surgical history came for a routine medical check-up. There were no specific findings on duodenoscopy and colonoscopy. An incidental mass, posterior to the stomach was seen on a chest computed tomography (CT). He was referred to the gastrointestinal center for further evaluation and treatment.

A contrast-enhanced abdominopelvic CT showed a well-defined heterogeneous-enhancing low-density mass abutting the stomach body and pancreas body (about $8.4 \mathrm{~cm}$ ) with multifocal calcifications (Fig. 1). Based on the appearance and enhancement pattern of the tumor, we diagnosed it as a gastrointestinal stromal tumor (GIST) of the stomach with extraluminal growth or an exophytic pancreatic neuroendocrine tumor.

An exploratory laparotomy using an upper mid-line incision was done. We explored the abdominal space and found a well-capsulated mass in the lesser omentum. There was no other specific finding. The mass and omentum surrounding the mass was entirely resected.

The well-circumscribed omental mass measured $8.5 \times 7.0 \times 5.0$ $\mathrm{cm}$ and weighed $202 \mathrm{~g}$. The surface of the resected specimen was gray-white and firm (Fig. 2). Neither hemorrhage nor necrosis were found. Microscopically, a patternless architecture of hypo and hypercellular areas separated by hyalinized collagen and vessels was observed (Fig. 3). Tumor cells showed small elongated nuclei and indistinct nucleoli. Mitotic figures were not found. The immu- 


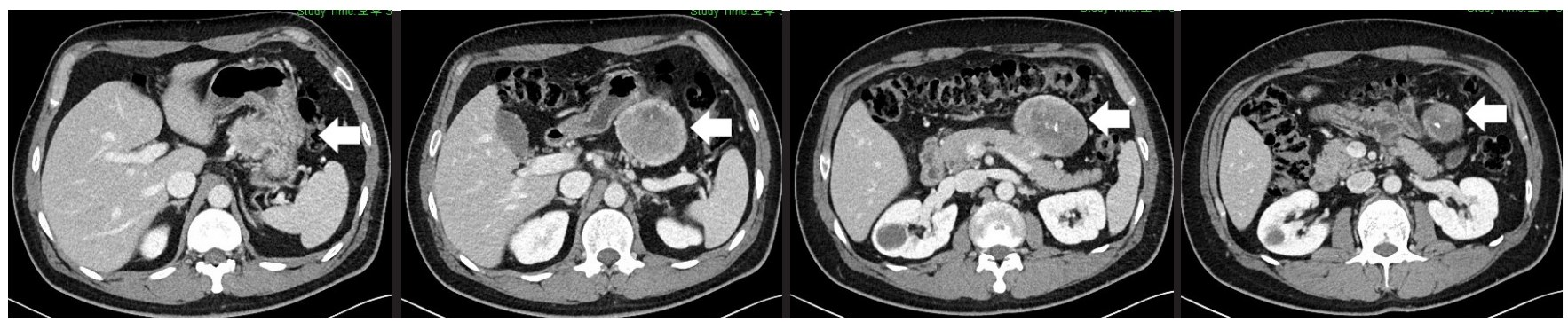

Fig. 1. Well-defined heterogeneous-enhancing low-density mass abutting the stomach body and pancreas body (about $8.4 \mathrm{~cm}$ ) with multifocal calcifications.

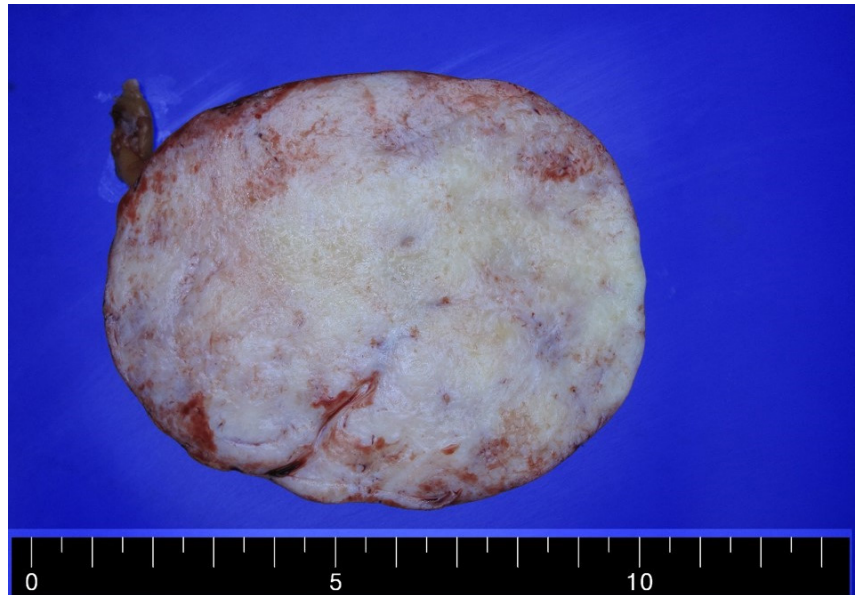

Fig. 2. The resected omental mass is gray-white and firm.
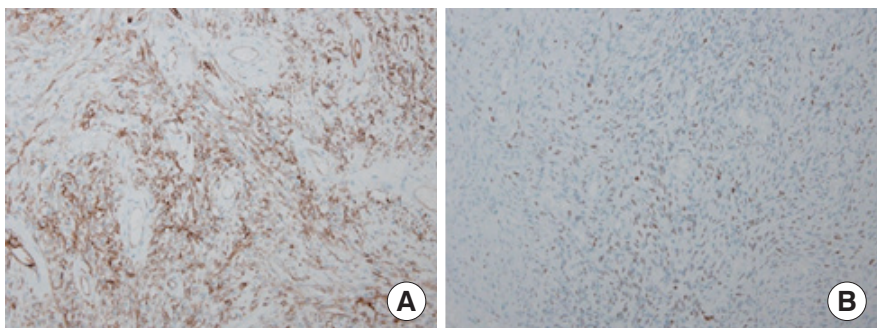

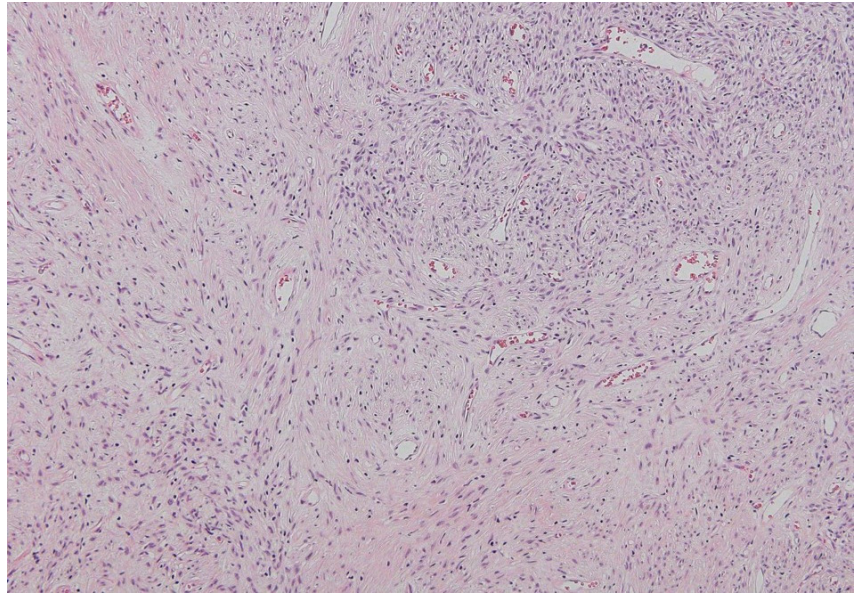

Fig. 3. Patternless architecture of hypo and hypercellular areas separated by hyalinized collagen and vessels is noted $\left(H \& E_{1} \times 100\right)$.
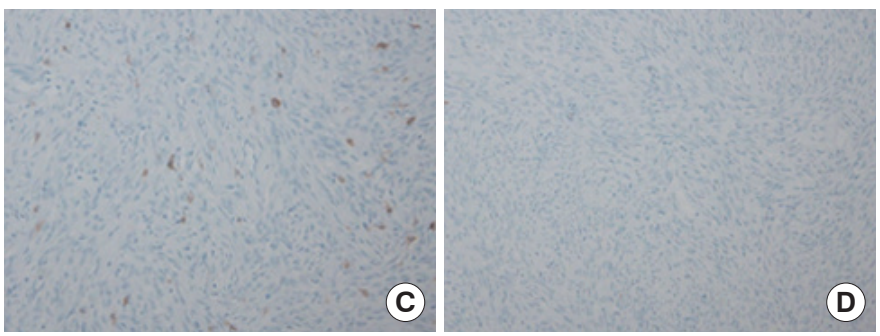

Fig. 4. Immunohistochemical stain was positive for CD34 $(A, \times 200)$ and STAT6 $(B, \times 200)$, but negative for CD117 (C, ×200) and S-100 (D, ×200).

nohistochemical stain was positive for CD34 and STAT6, but negative for CD117 and S-100 (Fig. 4).

\section{DISCUSSION}

SFT is a rare disease and only a few cases in the abdominopelvic cavity were reported in Korea. Among existing Korean reports, seven cases were found in the abdomen, one case in the spleen, three cases in the pancreas, one case in the stomach, and one case in the ischiorectal fossa. No case involving the lesser omentum was reported by searching KoreaMed (https://koreamed.org).
The diagnosis of SFT may be suspected based on imaging and clinical features. The imaging appearance of SFT arising in the abdominopelvic cavity has well defined margins. The mass may be lobulated, and there is generally a lack of gross infiltration into adjacent tissues, SFTs arising in visceral sites such as the liver or kidney typically manifest as a large well-defined heterogeneously enhancing mass with or without areas of necrosis. A capsule may be evident [5]. However, a definitive diagnosis requires histologic confirmation. It is difficult to differentiate GIST and SFT based on CT. The usual CT appearance of a GIST is a solid, smoothly contoured mass that enhances brightly with intravenous contrast. It 
may be difficult to identify the origin of a large mass because of exophytic growth. We diagnosed a well-defined heterogeneous-enhancing low-density mass abutting the stomach body and pancreas body as GIST because GISTs are most commonly found in the stomach (40\%-60\%) [9]. However, it was confirmed as an SFT by the immunohistochemical stains. Conventional immunohistochemistry markers of SFT include expression of CD34, $\mathrm{Bcl} 2, \mathrm{CD} 99$, and vimentin in the absence of actin, desmin, S-100 protein, or epithelial markers.

SFTs have a low rate of local recurrence and metastases after surgical treatment. Positive surgical margins and the presence of a histologically malignant component are predictive factors for worse local recurrence-free survival $[2,10,11]$. SFT recurrence may be due to incomplete resection [10]. Tumors seeding within the pleura, peritoneum, or meninges can spread via the hematogenous route. Therefore, complete resection is required. In addition, it is necessary to conduct a mass excision rather than biopsy if it is clinically suspected because a sufficient amount of tissue is required to confirm SFT.

SFT rarely occurs, but it could be potentially malignant, and surgical treatments have a good prognosis; therefore, it should be considered as a differential diagnosis for abdominal tumors.

\section{CONFLICT OF INTEREST}

No potential conflict of interest relevant to this article was reported.

\section{REFERENCES}

1. Klemperer P, Rabin CB. Primary neoplasms of the pleura: a report of five cases. Arch Pathol 1931;11:385-412.
2. Gold JS, Antonescu CR, Hajdu C, Ferrone CR, Hussain M, Lewis JJ, et al. Clinicopathologic correlates of solitary fibrous tumors. Cancer 2002;94:1057-68.

3. Gengler C, Guillou L. Solitary fibrous tumour and haemangiopericytoma: evolution of a concept. Histopathology 2006;48:63-74.

4. Wignall OJ, Moskovic EC, Thway K, Thomas JM. Solitary fibrous tumors of the soft tissues: review of the imaging and clinical features with histopathologic correlation. AJR Am J Roentgenol 2010; 195:W55-62.

5. Rosenkrantz AB, Hindman N, Melamed J. Imaging appearance of solitary fibrous tumor of the abdominopelvic cavity. J Comput Assist Tomogr 2010;34:201-5.

6. Chick JF, Chauhan NR, Madan R. Solitary fibrous tumors of the thorax: nomenclature, epidemiology, radiologic and pathologic findings, differential diagnoses, and management. AJR Am J Roentgenol 2013;200:W238-48.

7. Briselli M, Mark EJ, Dickersin GR. Solitary fibrous tumors of the pleura: eight new cases and review of 360 cases in the literature. Cancer 1981;47:2678-89.

8. Sung SH, Chang JW, Kim J, Lee KS, Han J, Park SI. Solitary fibrous tumors of the pleura: surgical outcome and clinical course. Ann Thorac Surg 2005;79:303-7.

9. Tran T, Davila JA, El-Serag HB. The epidemiology of malignant gastrointestinal stromal tumors: an analysis of 1,458 cases from 1992 to 2000. Am J Gastroenterol 2005;100:162-8.

10. Baldi GG, Stacchiotti S, Mauro V, Dei Tos AP, Gronchi A, Pastorino $\mathrm{U}$, et al. Solitary fibrous tumor of all sites: outcome of late recurrences in 14 patients. Clin Sarcoma Res 2013;3:4.

11. Demicco EG, Park MS, Araujo DM, Fox PS, Bassett RL, Pollock RE, et al. Solitary fibrous tumor: a clinicopathological study of 110 cases and proposed risk assessment model. Mod Pathol 2012; 25:1298-306. 